\title{
Education and patient preferences for treating type 2 diabetes: a stratified discrete-choice experiment
}

\author{
Ellen M Janssen' \\ Daniel R Longo ${ }^{2}$ \\ Joan K Bardsley ${ }^{3}$ \\ John FP Bridges' \\ 'Department of Health Policy \\ and Management, Johns Hopkins \\ Bloomberg School of Public Health, \\ Baltimore, MD, ${ }^{2}$ Department of Family \\ Medicine and Population Health, \\ Virginia Commonwealth University, \\ Richmond, VA, ${ }^{3}$ MedStar Health \\ Research Institute and MedStar \\ Nursing, Hyattsville, MD, USA
}

This article was published in the following Dove Press journal:

Patient Preference and Adherence

6 October 2017

Number of times this article has been viewed

Purpose: Diabetes is a chronic condition that is more prevalent among people with lower educational attainment. This study assessed the treatment preferences of patients with type 2 diabetes by educational attainment.

Methods: Patients with type 2 diabetes were recruited from a national online panel in the US. Treatment preferences were assessed using a discrete-choice experiment. Participants completed 16 choice tasks in which they compared pairs of treatment profiles composed of six attributes: Alc decrease, stable blood glucose, low blood glucose, nausea, treatment burden, and out-ofpocket cost. Choice models and willingness-to-pay (WTP) estimates were estimated using a conditional logit model and were stratified by educational status.

Results: A total of 231 participants with a high school diploma or less education, 156 participants with some college education, and 165 participants with a college degree or more completed the survey. Participants with a college degree or more education were willing to pay more for A1c decreases (\$58.84, standard error [SE]: 10.6) than participants who had completed some college $(\$ 28.47$, SE: 5.53$)$ or high school or less $(\$ 17.56$, SE: 3.55) $(p \leq 0.01)$. People with a college education were willing to pay more than people with high school or less to avoid nausea, low blood glucose events during the day/night, or two pills per day.

Conclusion: WTP for aspects of diabetes medication differed for people with a college education or more and a high school education or less. Advanced statistical methods might overcome limitations of stratification and advance understanding of preference heterogeneity for use in patient-centered benefit-risk assessments and personalized care approaches.

Keywords: preference heterogeneity, stated-preference methods, preference heterogeneity, willingness-to-pay, choice experiment, educational attainment

\section{Introduction}

The association between educational attainment and health outcomes is well known. ${ }^{1-3}$ In addition to life expectancy, ${ }^{4}$ education is associated with numerous mental and physical health outcomes, including diabetes. ${ }^{5}$ Diabetes is a chronic disease that affects 29.1 million people (9.3\%) and is the seventh leading cause of death in the US. ${ }^{6}$ Individuals with lower income and less education are two to four times more likely to develop diabetes ${ }^{7}$ and more likely to be affected by diabetes complications. ${ }^{8}$ While the prevalence of diabetes has gone up over time among all educational groups, diabetes remains more prevalent among people with lower educational attainment. ${ }^{9}$ In addition, treatments, such as intensive lifestyle interventions and medications, ${ }^{10} \mathrm{can}$ be more effective in people with higher educational attainment resulting in improved health outcomes.
Correspondence: Ellen M Janssen Department of Health Policy and Management, Johns Hopkins Bloomberg School of Public Health, 624 North Broadway, Room 690, Baltimore, MD 21205, USA

Tel + I 443287 I779

Email ejanssen@jhu.edu 
The association between education and health outcomes has been explained in several ways in the health economics literature. ${ }^{3,8}$ Schooling might increase the efficiency with which someone becomes and remains healthy. ${ }^{11}$ For example, a person with more schooling might recognize symptoms of an illness more quickly and therefore receive treatment more quickly. Schooling may affect how quickly people can obtain and process new information related to health care. ${ }^{12}$ Schooling might affect how well people follow and manage health care-related instructions, such as treatment guidelines. ${ }^{8,13,14}$ Schooling may also broaden social networks, including access to physicians. ${ }^{15}$ In the reverse association, health outcomes might influence educational attainment; people with poor health outcomes might have lower levels of education. ${ }^{16-18}$ This association is less likely to hold in the case of type 2 diabetes because type 2 diabetes is generally diagnosed later in adulthood when education has been completed. ${ }^{19,20}$

The education-health association might be mediated by treatment preferences (Figure 1). Educational attainment can affect treatment preferences ${ }^{21,22}$ and preference stability. ${ }^{23}$ Furthermore, patients' preferences might affect health outcomes. When patients' preferences are accommodated, greater adherence to therapy ${ }^{24}$ or feelings of control and greater health-related quality of life might result. ${ }^{25}$ In diabetes, time preference for the future is significantly related to diabetes complications. ${ }^{8}$ A link between patient preferences for treatment burden and adherence to diabetes medications has been shown. ${ }^{26,27}$ In addition, when physicians met their patients' preferences for information, patients with type 2 diabetes attained better metabolic control, selfreported adherence, and treatment satisfaction. ${ }^{28}$

Educational attainment has been shown to influence people's preferences for different types of diabetes selfmanagement programs. ${ }^{29,30}$ However, the link between

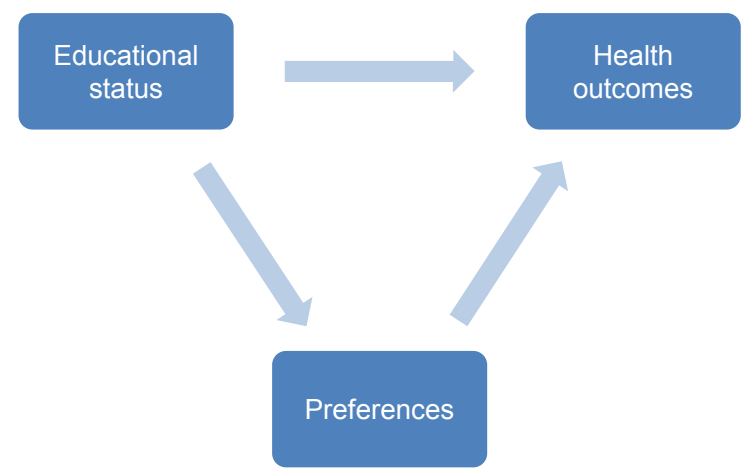

Figure I Conceptual model of relationship between educational attainment, preferences, and health outcomes. education and treatment preferences in diabetes needs to be further explored. In a preference study on diabetes treatment, Guimarães et al found that income was related to treatment preferences, but they did not find this link between educational attainment and treatment preferences. ${ }^{31}$ However, another preference study published by Hauber et al did find a difference in treatment preferences between people with some college education and no college education. ${ }^{27}$

This study examined the link between educational attainment and treatment preferences for type 2 diabetes medication by estimating separate willingness-to-pay (WTP) models for people who had completed high school or less education, who had completed some college, and who had completed college or more education. We hypothesize that people with more education are willing to pay more for diabetes medication. Understanding treatment preferences and WTP of patients with different levels of educational attainment might aid in informing and targeting patient-centered policies, treatment, and education efforts. The study illustrates an increasingly important research method for the measurement of patient preference and illustrates an approach to examine preference heterogeneity. In addition, it quantifies the preferences of patients with type 2 diabetes across the benefits, risks, and treatment burden of anti-glycemic medications.

\section{Methods}

Stated-preference methods are increasingly used to measure preferences of stakeholders in health care and to inform health care decision making..$^{32}$ In this study, treatment preferences for different aspects of diabetes medication were measured using a discrete-choice experiment (DCE). DCEs are one of the most common form of stated-preference methods, and guidelines have emerged for utilizing them. ${ }^{33-35}$ Our approach was consistent with existing guidelines and is summarized under four headings: conceptual model, creation of the choice tasks, survey respondents, and statistical analysis.

\section{Creation of the DCE choice tasks}

Treatment preferences for different aspects of diabetes medication were measured using a DCE. In a DCE, it is assumed that a treatment profile (in this case diabetes medication) is defined by a variety of characteristics, or attributes that can exist at different levels. Treatment profiles all contain the same attributes, but these attributes will present at varying levels. Respondents are asked to complete several choice tasks in which they are presented with one or more distinct treatment profiles. In these choice tasks, they are asked to select the treatment profile that they prefer more than the 
other profile(s). Based on participants' repeated choices, the relative preferences for the different attributes and levels can be estimated. An example of a DCE choice task is shown in Figure 2.

This DCE was specifically developed for the purposes of this study. The development process made use of a rigorous engagement process that included synthesis of the existing evidence, expert consultations, stakeholder engagement, qualitative pretest interviews ( $\mathrm{n}=25$ ), and quantitative pilot testing $(\mathrm{n}=27) .{ }^{36}$ First, attributes for the treatment profiles were identified, selected, and refined. Then, choice tasks were created and were tested with people with type 2 diabetes to determine whether they understood the attribute descriptions and could successfully complete the choice tasks. The final treatment profiles contained six attributes: Alc decrease $(0 \%$, $0.5 \%$, and $1 \%$ ), stable blood glucose ( 2 days per week, 4 days per week, 6 days per week), low blood glucose/hypoglycemia (none, during the day, during the day and/or at night), nausea (none, 30 minutes per day, 90 minutes per day), treatment burden (one pill per day, two pills per day, one pill and one injection per day), and out-of-pocket costs ( $\$ 10$ per month, $\$ 30$ per month, $\$ 50$ per month). The survey instrument included an explanation and example on how to complete a choice task. It also included detailed descriptions on all attributes and levels that had been pretested with people with type 2 diabetes to test their understanding of the concepts. It discussed the benefits of lowering A1c and the potential health consequences of high A1c levels.

With six attributes at three levels each, 729 distinct treatment profiles and more than 500,000 choice tasks containing two treatment profiles could be generated. Specialized software (Ngene, ChoiceMetrics) ${ }^{37}$ was used to select a subset of these possible choice tasks by estimating a D-efficient experimental design. Respondents were randomly assigned to one of three survey blocks that each contained 16 choice tasks. A sample choice task is presented in Figure 2.

\begin{tabular}{|c|c|c|}
\hline Attributes & Medicine A & Medicine B \\
\hline A1c levels go down by & $0 \%$ & $0.5 \%$ \\
\hline Stable blood sugar & 2 days per week & 6 days per week \\
\hline Additional low blood sugar events & During the day & None \\
\hline Nausea & None & 90 minutes per day \\
\hline Additional medicine & Two pills per day & One pill per day \\
\hline Additional out-of-pocket costs & \$10 per month & \$30 per month \\
\hline Which medication would you & I would choose & I would choose \\
\hline choose? & medicine A & medine B \\
\hline
\end{tabular}

Figure 2 Example of a discrete-choice experiment choice task.

\section{Statistical analysis}

The model was stratified by educational status by conducting separate analyses for participants who had completed high school or less education, participants who had completed some college, and participants who had a college degree or more education. Stata 13 (StataCorp LP, College Station, TX, USA) was used to analyze the data using a conditional logit model. ${ }^{38}$ The dependent variable represented whether a particular treatment profile was chosen. The independent variables were the attribute levels that made up the treatment profile. A1c decrease, stable blood glucose, nausea, and out-of-pocket costs were included as continuous variables. Low blood glucose and treatment burden were included as categorical variables, where no low blood glucose events and one pill per day served as the reference categories.

Preference estimates were converted to WTP estimates by taking the preference coefficient of each attribute level and dividing by the preference coefficient for cost:

$$
\mathrm{WTP}_{\text {attribute A }}=\frac{\beta_{\text {attribute } \mathrm{A}}}{\beta_{\text {cost }}}
$$

The WTP measures indicate how much patients would be willing to pay if a medication had a particular treatment attribute included in the DCE. A positive WTP value indicates that the attribute level is desirable and that participants are willing to pay for a medication with that attribute level. A negative WTP value indicates that the attribute level is undesirable and that a medication with that attribute level needs to cost less or participants need to be compensated to be willing to accept that attribute level. WTP measures were estimated separately for the different levels of low blood glucose and treatment burden. Standard errors (SEs) were estimated using the delta method. Paired $t$-tests were used to test for the equivalence of individual coefficients between educational groups.

WTP estimates were then converted into budget allocation estimates for each attribute. This budget allocation represented how much money out of a $\$ 100$ budget participants would be willing to allocate in order to ensure that a medicine had the desirable treatment attribute or did not have an undesirable treatment attribute. In this budget allocation, the absolute value of the WTP estimate of one attribute was divided by the sum of the absolute values of the WTP estimates of all attributes and multiplied by $\$ 100$ :

Budget Allocation $_{\text {attribute A }}=\frac{\left|\mathrm{WTP}_{\text {attribute A }}\right|}{\sum_{\mathrm{i}=\mathrm{A}}^{\mathrm{J}}\left|\mathrm{WTP}_{\text {attribute }}\right|} \times \$ 100$ 
This budget allocation was done to examine the priorities for treatment attributes of the different educational groups under standardized budgets and account for differences in WTP that might be found due to differing income levels. It only considered the most extreme levels for the categorical attributes (nausea, low blood glucose, and one pill and one injection) to avoid doubling up between attributes.

\section{Survey respondents}

Members of a nationally representative online panel with type 2 diabetes were invited by email to participate in the survey (GfK KnowledgePanel). All participants were required to be 18 years or older with self-reported physician-diagnosed type 2 diabetes and able to read English or Spanish. African Americans and Latinos were oversampled to account for the high prevalence of diabetes in these populations. ${ }^{39,40}$ Survey participants received compensation from the online panel equivalent to approximately $\$ 10$. Completion of the survey served as written informed consent from all participants. The Johns Hopkins School of Public Health IRB approved this study to be exempt from human subjects review (IRB 6001).

\section{Results}

A total of 552 people (66\% response rate) completed the survey. Our participants were more likely to take medication and were living with diabetes longer than a 2011 national sample. ${ }^{41,42}$ Of the total, 231 participants had completed high school or less education, 156 participants had completed at least some college, and 165 people had completed college or more education (Table 1). Participants with more education were more likely to be male, were more likely to report better health status, and had higher incomes. There were no differences between educational groups in years since diabetes diagnosis, having had a hypoglycemic event in the past 6 months, A1c levels, or medication use.

\section{WTP results}

Table 2 presents the WTP results stratified by educational attainment. Participants with high school education or less and participants with some college were willing to pay most to avoid having to take one pill and one injection a day (WTP for high school or less: \$-30.54, SE: 4.11; WTP for some college: \$-38.25, SE: 6.10). They were willing to pay least to avoid having to take two pills a day (WTP for high school or less: \$-5.22, SE: 2.89; WTP for some college: $\$-5.50$, SE: 3.43). Participants with a college degree or more were willing to pay most for a 1\% decrease in A1c (WTP: \$58.84, SE: 10.60). They were willing to pay least to avoid low blood glucose events during the day (WTP: \$-9.41, SE: 4.73).

Table I Characteristics of sample by educational attainment

\begin{tabular}{|c|c|c|c|c|}
\hline Characteristic & $\begin{array}{l}\text { High school or } \\
\text { less }(\mathbf{N}=23 \mathrm{I})\end{array}$ & $\begin{array}{l}\text { Some college } \\
(N=156)\end{array}$ & $\begin{array}{l}\text { College or } \\
\text { more }(N=165)\end{array}$ & $p$-value ${ }_{\mathrm{HS}=\mathrm{CO}}$ \\
\hline Age in years - mean (SD) & $61.58(11.27)$ & $61.03(12.57)$ & $61.18(11.54)$ & 0.89 \\
\hline Male - N (\%) & $100(43.3)$ & $86(55.1)$ & $93(56.4)$ & $0.015^{*}$ \\
\hline \multicolumn{5}{|l|}{ Race/ethnicity - N (\%) } \\
\hline White & $136(58.9)$ & $80(5 \mathrm{I} .3)$ & $73(44.2)$ & $<0.00 \mathrm{I}^{* *}$ \\
\hline Black & $34(14.7)$ & $45(28.8)$ & $47(28.5)$ & \\
\hline Hispanic & $56(24.2)$ & $28(17.9)$ & $35(21.2)$ & \\
\hline Annual income equal to or greater than $\$ 50,000-N(\%)$ & $78(33.8)$ & $77(49.4)$ & I I 7 (70.9) & $<0.00 I^{* *}$ \\
\hline Years since diabetes diagnosis - mean (SD) & I I.02 (7.73) & $10.90(7.85)$ & I I.88 (7.89) & 0.46 \\
\hline Self-reported health as good or better - N (\%) & $165(71.4)$ & $121(77.6)$ & $137(83.0)$ & $0.025^{*}$ \\
\hline At least one hypoglycemic event in the last 6 months $-\mathrm{N}(\%)$ & $109(47.2)$ & $76(48.7)$ & $74(44.8)$ & 0.78 \\
\hline Do not know their Alc level - N (\%) & $176(76.9)$ & $138(88.5)$ & $147(89.1)$ & $<0.00 I^{* *}$ \\
\hline Most recent Alc level more than $7.0 \%-N(\%)$ & $86(48.9)$ & $75(54.3)$ & $72(49.0)$ & 0.57 \\
\hline \multicolumn{5}{|l|}{ Type of diabetes medicine used - N (\%) } \\
\hline No prescription medicine & $20(8.7)$ & $9(5.8)$ & $8(4.8)$ & 0.32 \\
\hline Only pills & $135(58.4)$ & $98(63.2)$ & I 12 (67.9) & \\
\hline Pills and/or injections/shots & $76(32.9)$ & $48(31.0)$ & $45(27.3)$ & \\
\hline Minutes to complete DCE - mean (SD) & $13.39(11.15)$ & $14.08(18.50)$ & II.72 (7.69) & 0.23 \\
\hline \multicolumn{5}{|l|}{ Agree or strongly agree with the following statement - N (\%) } \\
\hline Choice tasks were easy to understand & I6I (69.7) & $106(67.9)$ & $124(75.6)$ & 0.27 \\
\hline Choice tasks were easy to answer & $152(66.1)$ & $99(63.5)$ & $100(61.0)$ & 0.58 \\
\hline Answers were consistent with my preferences & $185(80.1)$ & $126(80.8)$ & $133(80.6)$ & 0.98 \\
\hline Displayed lexicographic preferences - N (\%) & $42(18.42)$ & $19(12.26)$ & $15(9.2)$ & $0.027^{*}$ \\
\hline
\end{tabular}

Notes: *Significant at the 0.05 level. **Significant at the 0.01 level.

Abbreviations: DCE, discrete-choice experiment; HS, high school; CO, college; SD, standard deviation. 
Table 2 Willingness to pay for diabetes medication by educational attainment

\begin{tabular}{|c|c|c|c|c|c|c|c|c|c|c|}
\hline \multirow[t]{2}{*}{$\begin{array}{l}\text { Medication } \\
\text { attribute }\end{array}$} & \multirow[t]{2}{*}{$\begin{array}{l}\text { Medication level } \\
\text { change }\end{array}$} & \multicolumn{2}{|c|}{$\begin{array}{l}\text { HS diploma } \\
\text { or less } \\
(\mathrm{N}=23 \mathrm{I})\end{array}$} & \multicolumn{2}{|c|}{$\begin{array}{l}\text { Some } \\
\text { college } \\
(\mathbf{N}=156)\end{array}$} & \multicolumn{2}{|c|}{$\begin{array}{l}\text { College } \\
\text { or more } \\
(\mathrm{N}=165)\end{array}$} & \multirow[t]{2}{*}{$p$-value ${ }_{\mathrm{HS}=\mathrm{sc}} \mathrm{a}^{\mathrm{a}}$} & \multirow[t]{2}{*}{$p$-value ${ }_{s c=c o}{ }^{a}$} & \multirow[t]{2}{*}{$p$-value ${ }_{\mathrm{HS}=\mathrm{Co}}{ }^{\mathrm{a}}$} \\
\hline & & WTP & SE & WTP & SE & WTP & SE & & & \\
\hline Alc decrease & $1 \%$ & 17.56 & 3.55 & 28.47 & 5.53 & 58.84 & 10.60 & 0.08 & $0.01 * *$ & $<0.01 * *$ \\
\hline Stable glucose & 4 days per week & 23.12 & 3.88 & 29.82 & 5.06 & 35.00 & 8.17 & 0.29 & 0.59 & 0.15 \\
\hline Nausea & 30 minutes per day & -14.86 & 1.92 & -19.25 & 2.83 & -24.80 & 4.74 & 0.18 & 0.32 & $0.03 *$ \\
\hline Low glucose & None & 0 (ref) & & 0 (ref) & & 0 (ref) & & & & \\
\hline \multirow[t]{2}{*}{ events } & Day & -10.27 & 2.47 & -9.46 & 3.49 & -9.41 & 4.73 & 0.85 & 0.99 & 0.09 \\
\hline & Day/night & -16.62 & 2.88 & -19.95 & 4.00 & -31.65 & 7.51 & 0.49 & 0.18 & $0.04^{*}$ \\
\hline Treatment & One pill per day & 0 (ref) & & 0 (ref) & & 0 (ref) & & & & \\
\hline \multirow[t]{2}{*}{ burden } & Two pills per day & -5.22 & 2.89 & -5.50 & 3.43 & -16.22 & 4.47 & 0.95 & 0.06 & $0.03 *$ \\
\hline & $\begin{array}{l}\text { One pill and one } \\
\text { injection per day }\end{array}$ & -30.54 & 4.11 & -38.25 & 6.10 & -47.49 & 9.93 & 0.28 & 0.43 & 0.08 \\
\hline
\end{tabular}

Notes: andependent $t$-test for equivalence between WTP of educational groups. *Significant at the 0.05 level. **Significant at the 0.01 level.

Abbreviations: HS, high school; SC, some college; CO, college; WTP, willingness to pay; SE, standard error; ref, reference.

Participants with college or more were willing to pay more for A1c decrease than participants who had completed some college (\$28.47, SE: 5.53) or participants who had completed high school or less ( $\$ 17.56$, SE: 3.55$)(p \leq 0.01)$. People with a college degree or more were also willing to pay more to avoid 30 minutes of nausea ( $p=0.03$ ), low blood glucose events during the day and/or at night $(p=0.04)$, and to avoid two pills a day $(p=0.03)$ compared to people with high school or less. Other differences in WTP between educational groups were not statistically significant.

Figure 3 presents how people in different educational groups would allocate a budget of $\$ 100$ between the different aspects of diabetes medication. The biggest differences between educational groups could be seen in the allocation for A1c decrease. People with a college education or more would allocate $\$ 30$ for a $1 \%$ decrease in A1c, while people with some college would allocate \$21 and people with high school or less would allocate $\$ 17$.

People with some college or less education were willing to allocate more of their budget to 4 days of stable blood glucose a week than for a $1 \%$ decrease in A1c. People with a college education or more would allocate $\$ 24$ to avoid one pill and one injection a day, while people with some college would allocate \$28 and people with high school or less would allocate $\$ 30$. All groups would be willing to allocate the least (\$13-14) to avoid 30 minutes of nausea a day.

\section{Discussion}

In this study, a DCE was used to show that patients with type 2 diabetes do not only value reductions in their A1c levels but also had preferences for medications that stabilized their daily glucose levels and that reduced burden/

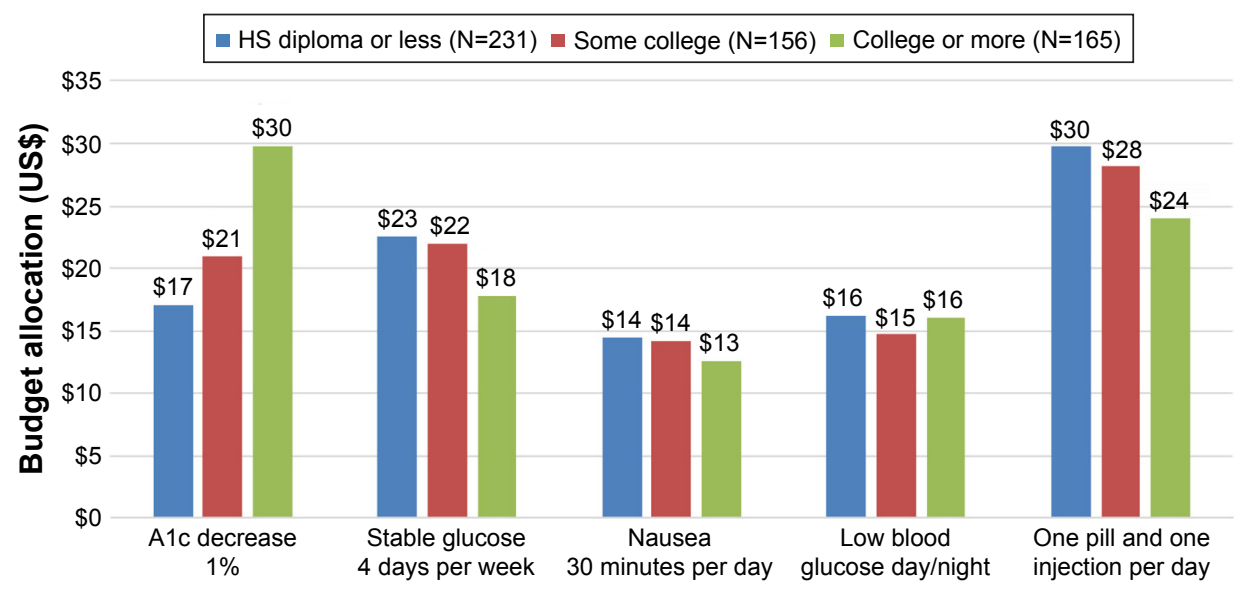

Figure 3 Budget allocation for diabetes medication by educational attainment. Abbreviation: HS, high school. 
harms of medication. Patients with different educational attainment displayed different preferences for diabetes treatment. Patients with a higher education were willing to pay more for all medication attributes than patients with lower educational attainment, possibly due to their higher average income. Differences in absolute WTP might not reflect differences in WTP as a proportion of earnings given that people with lower educational attainment generally also have lower earnings. ${ }^{43}$ However, absolute WTP is still an important measure of preference when making treatment decisions because it might reflect ability to pay and affect adherence to treatment.

This study calculated budget allocation estimates to account for differences in income and to examine the value of each aspect of diabetes medications relative to the other aspects. The results showed that on average patients with some college or less education prioritized reducing treatment burden; they were willing to allocate most of their budget to avoiding one pill and one injection per day. This priority could indicate that people with lower levels of education are more bothered by treatment burden which could decrease adherence if treatment burden is not considered in clinical care. ${ }^{44}$ People with some college or less education were willing to allocate more of their budget to 4 days of stable blood glucose a week than to a $1 \%$ decrease in A1c. This might indicate that patients with lower educational attainment might place more value on keeping their glucose levels within a daily target range rather than maintaining controlled A1c levels. As A1c control is generally the ultimate treatment goal in diabetes, ${ }^{45}$ treatment and education programs emphasizing reductions in A1c might be less effective in these populations ${ }^{10}$ as they are not aligned with the preferences of patients with lower levels of education.

Despite the high need for self-management in type 2 diabetes, much clinical research and care continues to neglect the patient perspective ${ }^{46}$ resulting in low rates of medication adherence $^{47}$ and low rates of achieving treatment goals. ${ }^{48}$ When incorporating the patient perspective, the effects of patient characteristics, such as educational attainment, on their treatment preferences should be considered. Efforts to deliver diabetes treatments may be more effective if tailored to individuals' preferences and educational background.

This study has several limitations. First, weight was not included as an attribute based on our instrument development process. This decision was partly made because weight gain could be interpreted as either positive or negative depending on the person and his/her current weight. While it is generally assumed that patients with type 2 diabetes would benefit from weight loss, this does not apply to some elderly, frail patients. To avoid estimation ambiguities that could arise due to this issue, and after consulting with diabetes experts and patients with diabetes, it was decided to not include weight changes as an attribute. Unless weight changes were dependent on one of the included attributes, this should not have affected the estimated importance of each attribute.

Second, a previous study found that people with lower educational attainment were less consistent in the choices they made in a DCE. ${ }^{49}$ If participants do not understand the choice tasks or attributes, they might be less consistent in the choices they make and their estimated preference weights are biased towards the null. In this study, people with a lower education were willing to pay less for every medication attribute. However, participants with lower educational attainment did not report that they had more difficulty with answering the choice tasks consistently. In addition, participants with lower educational attainment did not report more difficulty with understanding and/or answering the choice tasks. This suggests that their lower WTP is not due to lower choice consistency or lack of understanding.

Third, this study does not explore reasons why participants with lower educational attainment showed lower WTP for reductions in A1c. This limits implications for the tailoring of diabetes treatment to patients with lower educational attainment. If patients with lower educational attainment truly assign less value to reductions in A1c, this might indicate that diabetes treatment for these groups should focus on maintaining stable glucose levels on a daily basis or on reducing treatment burden. If patients with lower educational attainment have a more limited understanding about the importance of A1c and this decreases the value they place on reducing it, this might indicate that more educational efforts are necessary. Further studies, such as qualitative interviews, that explore this observed difference in preferences between people with different levels of educational attainment will help clinicians individualize diabetes treatment.

Finally, to maintain sufficient power, the analyses could not be controlled for other variables such as race/ethnicity, or income. Therefore, it is not clear whether observed differences in preferences were due to educational differences or other differences in the groups. A preliminary, stratified analysis by income showed that between two income groups (below $\$ 50,000$ and above $\$ 50,000$ a year), WTP differed only on A1c decrease and avoiding one pill and one injection per day, suggesting that education might play a more 
important role in treatment preferences. Segmentation techniques using finite mixture model $\mathrm{s}^{50,51}$ might be more appropriate to detect subgroup heterogeneity. These techniques group individuals based on the preferences they displayed in completing the preference instrument. The characteristics of people that make up these preference-based groups can then be observed to detect multiple factors, such as education, race/ethnicity, and income, that are predictive of belonging to a particular preference-based group.

\section{Conclusion}

This paper shows that while stratification methods can serve to identify differences in preferences based on observed characteristics, the number of possible subgroup analyses are limited. Preference researchers should be aware of this limitation of stratification methods. The findings in this study also suggest that diabetes patients with lower levels of education are willing to allocate more of their budget to avoid a higher treatment burden and that they might place more value on keeping their glucose levels within a daily target range than on lowering A1c. Being aware of patient preferences and that these preferences might vary by demographic characteristics can help clinicians tailor treatment approaches to patients by either adapting treatment or increasing educational efforts on the importance of lowering A1c.

\section{Key points}

- Stated-preference methods are a useful tool in evaluating how patients value different aspects of treatment.

- The study identified that patients with a college degree are willing to pay more for many aspects of diabetes medication than patients with a high school education or less, but further preference differences could not be explored.

- While stratification models are useful to detect differences in preferences by subgroup based on observed characteristics, they are limited in the number of subgroups that can be evaluated. Other statistical models should be explored to detect preference heterogeneity to better target clinical practice and health care decision-making based on treatment preferences.

\section{Acknowledgments}

The authors sincerely thank the Johns Hopkins Institute for Clinical and Translational Research (ICTR) Community Research Advisory Council (C-RAC) and members of the Diabetes Action Board (DAB) for their valuable contributions and engagement in the research study. This work was supported by a Patient-Centered Outcomes Research Institute (PCORI) Methods Award (ME-1303-5946) and by the Center for Excellence in Regulatory Science and Innovation (CERSI) (1U01FD004977-01). The funders had no role in the design and conduct of the study, interpretation of the data, or preparation of the manuscript.

\section{Disclosure}

The authors report no conflicts of interest in this work.

\section{References}

1. Hummer RA, Lariscy JT. Educational attainment and adult mortality. In: Rogers RG, Crimmins EM, editors. International Handbook of Adult Mortality. New York: Springer; 2011:241-261.

2. Mirowsky J, Ross CE. Education, Social Status, and Health. New York: Aldine de Gruyter; 2003.

3. Montez JK, Friedman EM. Educational attainment and adult health: under what conditions is the association causal? Soc Sci Med. 2015; 127:1-7.

4. Meara ER, Richards S, Cutler DM. The gap gets bigger: changes in mortality and life expectancy, by education, 1981-2000. Health Aff (Millwood). 2008;27(2):350-360.

5. Cutler DM, Lleras-Muney A. Education and health: evaluating theories and evidence. In: Schoeni RF, House JS, Kaplan GA, Pollak H, editors. Making Americans Healthier. Social and Economic Policy as Health Policy. New York: Russell Sage Foundation; 2008:29-60.

6. National Center for Chronic Disease Prevention and Health Promotion. National diabetes statistics report. 2017. Available from: https://www. cdc.gov/diabetes/pdfs/data/statistics/national-diabetes-statistics-report pdf. Accessed: September 6, 2017.

7. Hill J, Nielsen M, Fox MH. Understanding the social factors that contribute to diabetes: a means to informing health care and social policies for the chronically ill. Perm J. 2013;17(2):67-72.

8. Ayyagari P, Grossman D, Sloan F. Education and health: evidence on adults with diabetes. Int J Health Care Finance Econ. 2011;11(1) $35-54$.

9. Centers for Disease Control and Prevention. Age-adjusted percentage, adults with diabetes. Education. Available from: https://gis.cdc.gov/ grasp/diabetes/DiabetesAtlas.html. Accessed: September 9, 2017.

10. O'Brien MJ, Whitaker RC, Yu D, Ackermann RT. The comparative efficacy of lifestyle intervention and metformin by educational attainment in the Diabetes Prevention Program. Prev Med. 2015;77: $125-130$.

11. Grossman M. On the concept of health capital and the demand for health. $J$ Polit Econ. 1972;80(2):223-255.

12. de Walque D. How does the impact of an HIV/AIDS information campaign vary with educational attainment? Evidence from rural Uganda. J Dev Econ. 2007;84(2):686-714.

13. Smith JP. The impact of socioeconomic status on health over the lifecourse. J Hum Resour. 2007;42(4):739-764.

14. Goldman DP, Smith JP. Can patient self-management help explain the SES health gradient? Proc Natl Acad Sci U S A. 2002;99(16): 10920-10934.

15. Cutler DM, Lleras-Muney A. Understanding differences in health behaviors by education. $J$ Health Econ. 2010;29(1):1-28.

16. Case A, Fertig A, Paxson C. The lasting impact of childhood health and circumstance. J Health Econ. 2005;24(2):365-389.

17. Haas SA, Glymour MM, Berkman LF. Childhood health and labor market inequality over the life course. J Health Soc Behav. 2011;52(3): 298-313.

18. Palloni A. Reproducing inequalities: luck, wallets, and the enduring effects of childhood health. Demography. 2006;43(4):587-615. 
19. Centers for Disease Control and Prevention. Percentage, adults with diabetes. Age. Available from: https:/gis.cdc.gov/grasp/diabetes/ DiabetesAtlas.html. Accessed: September 6, 2017.

20. Centers for Disease Control and Prevention. National newly diagnosed diabetes. Rate per 1000, adults aged 18-79 years. 2017. Available from: https:/gis.cdc.gov/grasp/diabetes/DiabetesAtlas.html\#. Accessed: September 6, 2017.

21. Awad MA, Shapiro SH, Lund JP, Feine JS. Determinants of patients' treatment preferences in a clinical trial. Community Dent Oral Epidemiol. 2000;28(2):119-125.

22. Zickafoose JS, DeCamp LR, Prosser LA. Parents' preferences for enhanced access in the pediatric medical home: a discrete choice experiment. JAMA Pediatr. 2015;169(4):358-364.

23. Ditto PH, Smucker WD, Danks JH, et al. Stability of older adults' preferences for life-sustaining medical treatment. Health Psychol. 2003; 22(6):605-615.

24. Swift JK, Callahan JL. The impact of client treatment preferences on outcome: a meta-analysis. J Clin Psychol. 2009;65(4):368-381.

25. Street RL Jr, Voigt B. Patient participation in deciding breast cancer treatment and subsequent quality of life. Med Decis Making. 1997;17(3): 298-306.

26. Hauber AB, Han S, Yang JC, et al. Effect of pill burden on dosing preferences, willingness to pay, and likely adherence among patients with type 2 diabetes. Patient Prefer Adherence. 2013;7:937-949.

27. Hauber AB, Mohamed AF, Johnson FR, Falvey H. Treatment preferences and medication adherence of people with Type 2 diabetes using oral glucose-lowering agents. Diabet Med. 2009;26(4):416-424.

28. Cvengros JA, Christensen AJ, Cunningham C, Hillis SL, Kaboli PJ. Patient preference for and reports of provider behavior: impact of symmetry on patient outcomes. Health Psychol. 2009;28(6):660-667.

29. Casciano R, Malangone E, Ramachandran A, Gagliardino JJ. A quantitative assessment of patient barriers to insulin. Int J Clin Pract. 2011; 65(4):408-414.

30. Sarkar U, Piette JD, Gonzales R, et al. Preferences for self-management support: findings from a survey of diabetes patients in safety-net health systems. Patient Educ Couns. 2008;70(1):102-110.

31. Guimarães C, Marra CA, Colley L, et al. Socioeconomic differences in preferences and willingness-to-pay for insulin delivery systems in type 1 and type 2 diabetes. Diabetes Technol Ther. 2009;11(9):567-573.

32. Ho MP, Gonzalez JM, Lerner HP, et al. Incorporating patientpreference evidence into regulatory decision making. Surg Endosc. 2015;29(10):2984-2993.

33. Bridges JF, Hauber AB, Marshall D, et al. Conjoint analysis applications in health - a checklist: a report of the ISPOR Good Research Practices for Conjoint Analysis Task Force. Value Health. 2011;14(4):403-413.

34. Hauber AB, González JM, Groothuis-Oudshoorn CG, et al. Statistical methods for the analysis of discrete choice experiments: a report of the ISPOR Conjoint Analysis Good Research Practices Task Force. Value Health. 2016;19(4):300-315.

35. Reed Johnson F, Lancsar E, Marshall D, et al. Constructing experimental designs for discrete-choice experiments: report of the ISPOR Conjoint Analysis Experimental Design Good Research Practices Task Force. Value Health. 2013;16(1):3-13.
36. Janssen EM, Segal JB, Bridges JF. A framework for instrument development of a choice experiment: an application to type 2 diabetes. Patient. 2016;9(5):465-479.

37. ChoiceMetrics. NGene. User Manual and Reference Guide. 2014. Available from: https://dl.dropboxusercontent.com/u/9406880/Ngene Manual112.pdf. Accessed: September 6, 2017.

38. McFadden D. Conditional logit analysis of qualitative choice behavior. In: Zarembka P, editor. Frontiers in Econometrics. New York: Academic Press; 1974:105-142.

39. Centers for Disease Control and Prevention. National diabetes medication use. Age-adjusted percentage, diabetes population adult aged 18+ years. 2017. Available from: https://gis.cdc.gov/grasp/diabetes/ DiabetesAtlas.html\#. Accessed: September 6, 2017.

40. Centers for Disease Control and Prevention. National diabetes duration. Total-crude median, adults aged 18-79 years. 2017. Available from: https://gis.cdc.gov/grasp/diabetes/DiabetesAtlas.html\#. Accessed: September 6, 2017.

41. Cowie CC, Rust KF, Byrd-Holt DD, et al. Prevalence of diabetes and high risk for diabetes using A1C criteria in the U.S. population in 1988-2006. Diabetes Care. 2010;33(3):562-568.

42. Egede LE, Gebregziabher M, Hunt KJ, et al. Regional, geographic, and ethnic differences in medication adherence among adults with type 2 diabetes. Ann Pharmacother. 2011;45(2):169-178.

43. Bureau of Labor Statistics. Unemployment rates and earnings by educational attainment, 2016. 2017. Available from: https://www.bls.gov/ emp/ep_table_001.htm. Accessed: September 6, 2017.

44. Polonsky WH, Henry RR. Poor medication adherence in type 2 diabetes: recognizing the scope of the problem and its key contributors. Patient Prefer Adherence. 2016;10:1299-1307.

45. American Diabetes Association. Glycemic targets. Diabetes Care. 2016;39 Suppl 1:S39-S46.

46. Reaney M, Black P, Gwaltney C. A systematic method for selecting patient-reported outcome measures in diabetes research. Diabetes Spectr. 2014;27(4):229-232.

47. García-Pérez LE, Alvarez M, Dilla T, Gil-Guillén V, Orozco-Beltrán D. Adherence to therapies in patients with type 2 diabetes. Diabetes Ther. 2013;4(2):175-194.

48. Pérez CM, Febo-Vázquez I, Guzmán M, Ortiz AP, Suárez E. Are adults diagnosed with diabetes achieving the American Diabetes Association clinical practice recommendations? P R Health Sci J. 2012; 31(1):18-23.

49. Lancsar E, Louviere J, Donaldson C, Currie G, Burgess L. Best worst discrete choice experiments in health: methods and an application. Soc Sci Med. 2013;76(1):74-82.

50. McFadden D. The choice theory approach to market research. Market Sci. 1986;5(4, Special Issue on Consumer Choice Models):275-297.

51. Swait J. A structural equation model of latent segmentation and product choice for cross-sectional revealed preference choice data. J Retail Consumer Serv. 1994;1(2):77-89.
Patient Preference and Adherence

\section{Publish your work in this journal}

Patient Preference and Adherence is an international, peer-reviewed, open access journal that focuses on the growing importance of patient preference and adherence throughout the therapeutic continuum. Patient satisfaction, acceptability, quality of life, compliance, persistence and their role in developing new therapeutic modalities and compounds to optimize

\section{Dovepress}

clinical outcomes for existing disease states are major areas of interest for the journal. This journal has been accepted for indexing on PubMed Central. The manuscript management system is completely online and includes a very quick and fair peer-review system, which is all easy to use. Visit http://www dovepress.com/testimonials.php to read real quotes from published authors. 